\title{
MATHEMATICS TEACHERS' POSITIONS AND PRACTICES IN DISCOURSES OF ASSESSMENT
}

Candia Morgan

Anna Tsatsaroni

Stephen Lerman

Work carried out at:

Institute of Education, University of London

20 Bedford Way

LONDON WC1H OAL

$\underline{\text { Address for proofs, correspondence and offprints: }}$

Dr Candia Morgan

Mathematical Sciences

Institute of Education, University of London

20 Bedford Way

LONDON WC1H 0AL 


\section{SUMMARY}

Recent curriculum reforms have led to a wider variety of methods of assessment in formal 'high stakes' assessment regimes in many countries. Morgan's (1998) study of mathematics coursework assessment in UK schools identified a number of positions adopted by teachers as they assessed student texts. Using Bernstein's theoretical framework, we revisit Morgan's study in order to construct a model for understanding teachers' assessment practices and positionings. The model consists of opposing forms, generated by modelling agencies, agents, practices and specialised forms of communication, to identify their principles of construction, displayed as changes in the strength of boundary. This helps to distinguish practices of assessment as different modalities of regulation, and to understand the tensions within and between discourses and practices. Thus, for example, by interpreting tensions between discourses of 'mathematical investigation' and of 'assessment' in terms of the contradictory demands made by different modes of pedagogic practice, we can reveal the social assumptions of the pedagogic discourse. 


\section{BIOGRAPHICAL DETAILS}

Candia Morgan is Senior Lecturer in Mathematics Education at the Institute of Education, University of London, working with in-service and pre-service mathematics teachers. Her research interests include assessment practices in mathematics education, language in mathematics education, and the use of critical discourse analysis in educational research. She is the author of Writing Mathematically: The Discourse of Investigation (Falmer Press) and a number of articles in the area of mathematics education.

Anna Tsatsaroni is Assistant Professor in the Department of Early Childhood Education, University of Patras, Greece. Her research interests are in the sociology of scientific knowledge, sociology of school knowledge, and theoretical issues in social science. She is the author of a number of articles in the area of the sociology of science and mathematics education, in collaboration with educators in these fields, focusing on the analysis of pedagogical texts and practices.

Stephen Lerman is Professor of Mathematics Education at South Bank University in London and Head of Educational Research. He was President of the International Group for the Psychology of Mathematics Education from 1995 to 1998 and Chair of the British Society for Research into Learning Mathematics from 1994 to 1996. His research interests include: philosophy of mathematics; teacher education; equity issues; learning theories; and sociocultural analyses of mathematics teaching and learning. 


\section{MATHEMATICS TEACHERS' POSITIONS AND PRACTICES}

\section{IN DISCOURSES OF ASSESSMENT ${ }^{1}$}

\section{INTRODUCTION}

At all stages of schooling, students are subject to evaluation - by their teachers and, through externally devised tests and examinations, by other agents. The results of such evaluations have profound consequences for students, affecting their future educational experiences and further educational and employment opportunities. This is particularly the case for mathematical attainment as a qualification in mathematics is often used as a necessary criterion for entry into further education or employment. At the same time, evaluation has important consequences for teachers. As well as being concerned for their students' wellbeing, teachers are likely to be judged professionally through evaluations of their students' achievements.

Recent mathematics curriculum developments in a number of countries have led to the inclusion in formal assessment regimes (leading to 'high stakes' consequences for students and teachers) of a wider variety of methods of assessment, including 'performance' and 'authentic' assessment (e.g. Romberg, 1995). There has been a move away from traditional tests and examinations towards tasks that allow more varied, complex responses. This move

\footnotetext{
${ }^{1}$ The work reported here has been supported in part by the authors' participation in the project Teaching and Learning - Mathematical Thinking, Fundação para Ciência e Tecnologia, grant no. PRAXIS/P/CED/130135/98
} 
has simultaneously increased the complexity of the task of assessing student responses - a task generally undertaken by teachers, who must interpret the texts (written, spoken or behavioural) produced by their students in order to evaluate them.

Most existing research on assessment in mathematics education has been concerned with the development and validation of assessment instruments or the degree of reliability in assessment by teachers (see Morgan, 2000a; 2000b). Studies at the detailed level of individual teachers' assessment practices suggest that there can be substantial differences not only between evaluations made by different teachers but also in the approaches they take to the task of assessment (Morgan, 1996; Watson, 1999). Morgan attempted to make sense of these differences by identifying a number of positions adopted by teachers during the process of assessing student texts, encompassing different relationships to students and to external authorities and different orientations towards the texts and the task of assessment. In this paper, we revisit Morgan's study in order to clarify the notion of positioning and to construct a framework for understanding mathematics teachers' assessment practices. In doing this, we draw on the work of Bernstein.

Bernstein's writings $(1990 ; 1996)$ offer a framework for systematic study of educational data informed by theoretical considerations that bring together macro-sociological analyses with their realisation in the classroom. His work provides a language for description of the pedagogic mechanism through which education reproduces social inequality. This mechanism comprises forms of curriculum, pedagogy and assessment, the final element being the focus of this paper.

We will be using examples from the assessment of GCSE coursework as studied by Morgan (1998). The General Certificate of Secondary Education (GCSE) is the examination taken by almost all students in England and Wales at age 16+. Schools enter their students for one of a 
choice of syllabuses offered by a small number of examination boards. These boards are independent commercial bodies, but all syllabuses must be approved by the Qualifications and Curriculum Authority, a government agency. The mathematics GCSE includes a coursework element, which most commonly takes the form of written reports of work on one or more investigative tasks. While a timed examination element is marked by external examiners, students' own teachers assess the coursework and these assessments are moderated by the boards. Teachers are provided with official criteria and 'performance indicators' from the boards but they may also draw on ideas from their training and previous teaching experience as well as more general ideas from the media or from 'common sense' discourses.

\section{BACKGROUND}

Morgan's (1998) study of teachers assessing students' coursework attempted to describe the ways in which teachers read student texts. Empirical analysis of interviews during which teachers read and assessed student texts suggested that the teachers drew on resources from different, sometimes contradictory, discourses and that the various ways they were positioned within these discourses could lead to different evaluations of the same student text. The analysis identified the following positions:

- $\quad$ examiner, using externally determined criteria

- $\quad$ examiner, setting and using her own criteria

- $\quad$ teacher/advocate, looking for opportunities to give credit to students

- teacher/adviser, suggesting ways of meeting the criteria

- teacher/pedagogue, suggesting ways students might improve their perceived levels of mathematical competence 
- $\quad$ imaginary naïve reader

- interested mathematician

- interviewee

Teachers were found to adopt one or more of these positions as they evaluated student work and justified their evaluations (see Morgan, 1998, pp. 134-137).

Further examination of the data enabled us to identify some of the discourses on which the teachers appeared to be drawing in order to make sense of and evaluate students' texts. We illustrate this with the following extract from an interview with an experienced teacher, Fiona, reading a student coursework text:

. . but again even that's not, I mean he's given . . one thing that I think they have to do is when they give a formula they should explain it using quite a few examples and show how it works. The thing that I always look for and I say to the kids is: you write it up as if you're writing it for somebody who's never seen this problem, [...] I don't think it's clear enough for somebody to use it and then work out, I mean he hasn't done even one example of how it works.

The original analysis of Fiona's positioning saw her as shifting between several positions: as an examiner, as a teacher/adviser, an imaginary naïve reader and an interviewee. Revisiting the data we ask: how is Fiona positioned in relation to the official discourse of the examination and what resources, from which discourses, does she draw on in order to make sense of the practice of assessment? For example, the official discourse of the examination includes 'clear communication' among its evaluation criteria. Fiona appears to be accepting and applying this criterion but she is recontextualising it, making sense of it by drawing on resources from other discourses, specifically an everyday notion of communication as 
transmission of meaning as well as her teacher knowledge of 'explaining' as providing examples that will enable the reader to complete similar problems. She also draws on her everyday teaching experience - "the thing I always look for and I say to the kids ...".

In this paper, we seek to construct a theoretical model, drawing on Bernstein's work, to identify and explain the positions available to teachers within assessment practices and to address the question of how the official discourse of assessment, including the explicit criteria provided for teacher-assessors, may be transformed within the school as teachers such as Fiona make sense of their practice by drawing on the various resources available to them.

\section{THEORETICAL CONSIDERATIONS}

To understand how teachers engage in assessment practices, we need to be able to describe systematically the field, the sub-fields, the agents acting in them and the social relations through which pedagogical and other educational discourses are constructed, and practices distributed. Bernstein's theoretical model provides us with a set of concepts for such a systematic description.

Within the pedagogical field, we can, first, distinguish the sub-field where pedagogical discourses are constituted through processes of recontextualisation of knowledge and practices. This is of major importance for our understanding of how such discourses are formed because it helps us to focus our analysis on the agents responsible for a particular recontextualisation, the resources used and the processes of selection, simplification, condensation, repositioning and refocusing (Bernstein, 1990), through which a discourse is transformed, and a pedagogical discourse formed and used in contexts different from its substantive context.

An example is school mathematics, a pedagogic discourse formed through the recontextualising 
of the specialised discourse of Mathematics. Such a recontextualisation is driven by a purposeful intention to initiate, develop or change knowledge by somebody who already possesses or has access to the necessary resources, and the means of evaluating the acquisition of the discourse (Bernstein and Solomon, 1999). Another example is the discourse of evaluation, an educational discourse regulating the activity of assessment of acquisition of school mathematics. This is the product of recontextualisation of elements from other discourses, knowledge and practices, which are much more difficult to identify, and which provide teachers (and pupils) with forms and criteria of good or appropriate practice. Obviously there are multiple, often difficult to track down, links between the two discourses of pedagogy and of evaluation; and sometimes an explicit discourse of assessment is not prevalent (see Bernstein, 2000; Broadfoot, 1996; 2000). In this paper we focus on the evaluation discourse.

\section{The production and operation of evaluation discourse}

The discourse of evaluation is not unitary but consists of an official discourse and other unofficial discourses. We shall attempt to discern the nature of the discourses of evaluation, within which teachers in Morgan's study, briefly described earlier, carry out the activity of assessment, how these discourses are produced and how they operate.

The official discourse of evaluation is produced by agents operating in the Official Pedagogic Recontextualising Field (OPRF) (Bernstein, 1996), for example, the examination boards, government departments and agencies. To produce this discourse, official agents have drawn on a set of discourses and practices, available within the sub-field of recontextualisation, and have subsumed them under their own aims and purposes. Among such discourses are those produced in the field of production of knowledge by the activities and practices of the mathematics education research community and circulated within the Unofficial Pedagogic Recontextualising 
Field (UPRF) (Bernstein, 1996) such as teacher training courses. Elements of these are appropriated by official agents, often constituting central elements of the official discourse. Elements of discourses produced by other educational communities and circulated within the UPRF, such as discourses on school management, school effectiveness, etc., might also become elements of the official discourse. Therefore the official discourse of evaluation consists of a variety of elements from heterogeneous discourses, including those of mathematics and other education research, inspection reports, productions of other government agents, parents, and wider social discourses. However, discourses produced by the mathematics education research and other communities might remain outside the official pedagogic discourse, forming unofficial, oppositional educational discourses on evaluation.

Figure 1 here

We can argue, then, that the guidelines, procedures and criteria of assessment of coursework in Morgan's study, are products of such processes of recontextualisation and elements of the official discourse on evaluation. For example, the guidelines for assessment of coursework provided by one of the examination boards discuss the use of oral evidence. These guidelines draw on arguments, produced within the mathematics education research field and circulated within the UPRF, that students' oral and written texts are equally valid sources of evidence of mathematical achievement (e.g., MacNamara \& Roper, 1992). Thus it is stated that:

credit can be given for remarks made orally but not necessarily written down

But the guidelines also draw on elements of official discourse on evaluation that give priority to written texts: 
For instance, a candidate might be able to express a strategy well orally but lack some of the skill required to communicate the strategy in other ways.

and:

When credit is given for something expressed orally it is sensible for the teacher to record this ... This will greatly help the process of moderation. (Edexcel, 1999, p.12)

What does this discourse do? It suggests to teachers (or attempts to impose on them) practices and criteria of assessment, and provides them with arguments to make sense, justify and explain their practices to pupils, parents, official moderators, and interested others. Following Bernstein, we can say that this discourse attempts to regulate teachers' practices of assessment.

It is crucial to ask how the discourse on coursework assessment positions teachers (and pupils). Assessment of coursework, in contrast to traditional, formal, timed examinations, is completed by students in class, and in their own time. Thus its pacing is slower, compared to the timed examination, and the investigation tasks may vary, depending on the specific, local interests of pupils and teachers. Furthermore, whereas formal examinations are marked by external examiners who do not know the students, the coursework is marked by the classroom teacher, who is expected to know the students and is committed to regulating their progress. Compared to formal examinations, therefore, coursework is less strongly classified and framed (Bernstein, 1971) such that it looks more like a learning exercise than an assessment task of students' acquisition of mathematics. Thus we note that, on the one hand, teachers are provided with official criteria and 'performance indicators' from the examination boards; and that examination boards keep the control over the process of coursework assessment through the mechanism of moderation. These measures serve to draw a strong boundary between the examination board (and the related official agency) and teachers, constituting official agency as a strong voice. On the other hand, the weaker classification and framing of the task of coursework assessment, per 
$s e$, make it appear as if teachers have the power to exercise judgement as to what resources to use to construct such tasks, when to implement them within the classroom, how much time to allocate, what constitutes admissible help, what account to take of achievement evidenced in ways that are not recorded in the student's formal written report. This seems, somehow, to weaken the official voice, seemingly allowing for interpretation and discretion at the local level. We are therefore arguing that teachers' positioning in the official discourse is a function of the degree of boundary maintenance (Bernstein, 2000) that regulates the relation between official agents on the one hand, and other agents (such as educational advisers, researchers, mathematics teacher educators) and teachers on the other. In this case the boundary is in some respects strong, and in other respects less strong and, as we will show below, this affects teachers' positions within and their degree of affiliation to the discourse.

A second aspect of the production of discourse is that among its constitutive elements are theories, evidence, arguments, in short projections of practice produced by agents operating in the mathematics education research field of production (see Figure 1). As argued, these knowledges become resources that the official discourse of evaluation draws on to prescribe assessment tasks and procedures and forms of pedagogical relationships, though these are subject to recontextualisation and multiple transformations. These can also relay different and at times oppositional voices.

There are a number of issues regarding the field of mathematics education research and its relationship to the official evaluation discourse, notably its status and its internal organisation. To start with its status: mathematics education research comprises a sub-field within the general field of educational studies in the field of intellectual production. Though small, this sub-field is continually growing nationally and internationally and, relative to other sub-fields, enjoys some significance in the field of educational studies. On the other hand, within the general field of 
intellectual production, educational studies is a most vulnerable area, subject to interventions by the state, as a consequence of current economic, cultural, technological and social changes, reducing its significance.

The second issue is the way its knowledge is organised. That is to say, as well as the external relations of the sub-field of mathematics education research we should consider its internal structure. This structure is shared with the field of educational studies more generally. We can identify two models, performance and competence pedagogical models. Within the competence model there are several modes: the liberal-progressive mode, focused on the cognitive empowerment of the individual; a populist mode, backed by sociological approaches, and a more elaborate version, the radical-emancipatory mode, backed by critical social theories (Lerman \& Tsatsaroni, 1998). In the 1990s, competence models have tended to be replaced by new performance models, legitimated by instrumental, managerial discourses.

While it cannot be assumed that such modes and models are clearly identifiable in the field of education research and its sub-fields they, nevertheless, help to reveal the internal structure of (mathematics) education research which, in Bernstein's terms, is a horizontal knowledge structure with a weak grammar (cf. Bernstein, 1999; Lamnias \& Tsatsaroni, 1999). This means that, unlike hierarchical knowledge structures, exemplified by the natural sciences, which are motivated towards greater and greater integrating propositions, operating at more and more abstract levels, mathematics education research consists of a series of specialised languages with specialised modes of interrogation and criteria for the construction and circulation of texts. Developments take the form of the addition of a new language, an additional segment, rather than greater generality and integrative potential.

The character of the (mathematics) education research field as a horizontal knowledge structure with a weak grammar directs our attention to consequences that are crucial for our 
considerations in this paper. These consequences are linked to what Maton (2000), elaborating and extending Bernstein's notion of weak and strong grammars, calls the 'language of legitimation' for new knowledge production in a given field. For Maton, a language of legitimation comprises an articulation of an epistemic and a social relation. The former refers to what may be claimed knowledge of and how, while the latter refers to who may claim knowledge. According to this definition, intellectual fields with weak grammars are those which specialise and privilege positions within the field on the basis of who is making the claim to knowledge (the social relation) rather than the epistemic relation. Maton calls this a "knower mode' and contrasts it to a 'knowledge mode' of legitimation, where the articulation of the epistemic and social relation is reversed. Hence the serial or segmental character of knowledge based on knowledge structures with a weak grammar, and the way that they tend to develop and change, that is, by addition of new specialised languages.

Accordingly, what we described earlier as competence and performance models and modes, and the 'switch' from one to another, can be seen as attempts to weaken or strengthen the grammar for knowledge production and change (cf. Moore and Maton, 2001). More specifically, performance models can be understood as effects of a language of legitimation with relatively strong grammar: they represent a tendency towards a 'knowledge mode'. In contrast, competence models exemplify the weakening of the knowledge structure and a switch towards a 'knower mode' of legitimation.

Weakening or strengthening of the grammar of an intellectual field of knowledge production, in our case the tendency to 'switch' from performance to competence models and the reverse, has important consequences. With strengthening (performance models), there is an emphasis on knowledge, on the product/text of pupils, while weakening (competence models) entails a shift to the pupil her/himself. In the latter case, as Maton also shows in his analysis of the field of 
cultural studies, the researcher (and ultimately the teacher) is meant to stand for, have privileged access to, or represent the interests of usually marginalised individuals or social groups: to 'give voice to' those who occupy a dominated social position (Moore and Muller, 1999).

Thus the status and organisation of knowledge in the field of mathematics education research points to the shifting and uncertain nature of the field. This affects voice constitution and power relations and makes positioning precarious since there is no stable single specialised language, therefore no clear distinction between official and oppositional discourses. Instead there are complex relationships between the official voice and other voices. Coursework exemplifies this. The official discourse of evaluation draws mainly on and recontextualises elements from the liberal-progressive mode. This apparently gives autonomy to teachers vis-à-vis the official educational agency and shifts responsibility to them: the liberal-progressive mode places value on pupils and their internal processes rather than on their finished product; it orientates teachers to look for evidence of pupils' progress and development, i.e., what is present in the work; and it suggests criteria of assessment which are multiple and diffuse. Thus the voice of the official discourse is not imperative and authoritative, while the voice of weaker students, e.g. those who would find it difficult to compete in national, high-stakes assessment conditions, is listened to and given a chance. However, the elaboration of official criteria of assessment, at the national level, is a move in the opposite direction. Formal and explicit criteria are an element of reemerging performance models which are thus valorised. By drawing on these resources, the discourse re-institutes the authority and power of the official voice. Pre-given criteria of assessment orientate teachers towards pupils' finished products, and what is absent from these products. The voice of the dominated or of the weak participant in the pedagogic relationship is suppressed. 


\section{The recontextualisation of the discourse of evaluation in the mathematics classroom}

A further important aspect of the discourse is how it is deployed in practice. Bernstein stresses that it is crucial to distinguish between two kinds of transformation of elements of discourse, when they become subjected to recontextualisation processes. The first, already referred to, is the transformation of discourses and the construction of an official discourse of evaluation. The second is the transformation of this new discourse, as it becomes active in the pedagogic process and the mathematics classroom. In order to examine the deployment of the discourse in practice, we analyse teachers' positions within it, that is to say, their position vis-à-vis the official discourse, the resources on which they draw and their assessment practices, i.e., the criteria and their orientation to the task.

What affects the recontextualisations at this level is a crucial question. What are the resources teachers use to construct their position and deploy 'appropriate' practice? We have already argued that both the official discourse of evaluation (including elements from the specialised (mathematics) education discourse) and the specialised languages of (mathematics) education research field, independently available within UPRF (see Figure 1), are resources for teachers. But in addition, the strategies they develop in doing their tasks, and in justifying their practices, depend on how they interpret their own schoolwork activity. Strategies may be drawn from vertical or horizontal discourses. Horizontal discourse refers to forms of knowledge usually typified as everyday or common sense; while vertical discourse refers to knowledge forms whose circulation is subject to distributive rules regulating access, transmission and evaluation. Discourses about teachers' professional development and work have at times stressed the very specialised and elaborate knowledge structure which should underpin their performance (e.g., developmental psychology). In contrast, current professional discourses conceive of teaching as a localised activity, based on teachers' day-to-day personal experiences and reflective processes. 
Resources drawn from these two distinct vertical discourses prescribe very different forms of action and behaviour for teachers. Moreover, these contrast with resources drawn from other, local contexts in which teachers live and act. Such discourses, we argue, are additional resources for teachers and provide them with strategies and the means to argue for and justify their decisions and actions concerning the assessment of their pupils (cf. Ensor, 1999).

\section{BUILDING THE MODEL - THE RESEARCH TOOL}

Morgan's study of teachers assessing students' coursework as described earlier has identified empirically a number of positions adopted by teachers as they evaluated students' work. We shall now use our theoretical sources and the set of concepts introduced above to attempt to build a model, to re-address the same set of data and to be applicable more generally.

Our theoretical considerations indicate that the official discourse of evaluation shapes teachers' assessment activity, constructing teachers' positions and forms of practice, and that structurally there are two (pre-)dominant subject positions for teachers: speaking the voice of the official (legitimate) discourse of evaluation, or speaking the voice of other discourses. Therefore, the central question that directs our attempt to build the model is: Do teachers accept or reject the official discourse?

Though compulsory, with "clear" criteria, moderation processes, etc., teachers' resistance to the official discourse of evaluation is always a possibility. This resistance is easier to trace in the context of interviewing. However, we do not consider worth pursuing the question of the difference between the situation of interviewing and their activity of assessment as deployed in teachers' local contexts. Rather it is much more productive to describe:

- teachers' orientation towards pupils' coursework as a task and their own task of 
assessing coursework

- the resources they draw on to understand and interpret these tasks;

- the kind of strategies they deploy in acting and justifying their decisions and judgements.

Figure 2 presents a four dimensional model. In the main matrix, the rows represent the two structural positions of the discourse of evaluation ('voice' constitution): the position of teachers speaking the voice of the official discourse of evaluation, and the position of teachers speaking the voice(s) of other discourses. The columns represent forms of practice, defining teachers' orientations and strategies. Again, two oppositional forms of practice can be identified: orientation towards the text produced by the student, as in performance models, and orientation towards the student, as in competence models. This is when discursive resources are drawn on 'consistently', though all four positions in the model are possible.

Embedded within the first is a second matrix, which represents 'strategies' (cf. Dowling, 1998), according to the focus directing teachers' actions, and the level of generality of their commentary (cf. Brown, 1999). The rows represent teachers' focus towards what is present or absent. Again, while there are two logical possibilities, a teacher who uses resources 'consistently' would tend to focus on what is absent (i.e. what is lacking in the text), if his/her orientation is defined by performance models. Likewise, a teacher would tend to focus on what is present (i.e. what qualities the student exhibits), if his/her orientation is defined by competence models. The columns represent the level of generality of teachers' comments, ranging from localised to specialised judgements. Depending on whether they perceive of their activity as a specialised or an everyday one, drawing on vertical or horizontal discourses respectively, teachers would tend to justify their evaluation of a student by reference either to pedagogic principles and theories or to common sense notions.

The structural position in the model and in particular the form of practice, defined in terms of 
orientation and strategies, will, in turn, affect the criteria used by teachers and their degree of explicitness. The possibilities here range from explicit adoption, or implicit reinforcement of the criteria of the discourse, to explicit rejection of the criteria of the official discourse and adoption of alternative criteria, and their interpretation (or re-interpretation) according to everyday resources.

Questions of contradictory demands created by different resources and of the tendency to interpret the criteria adopted through resources drawn from the horizontal discourse are pertinent here. For example, use of criteria would be 'consistent' if a teacher, with an orientation towards the student, a focus on presences, using specialised commentary, all according to a pedagogic model of competence, acts in ways that keep his/her criteria implicit, and uses multiple and defuse criteria interpreted through recourse to theories informing this pedagogic model. Furthermore, for the overall position to be 'consistent', the structural position adopted would draw only on resources from the same model. However, there is likely to be a tendency for teachers to reinterpret the criteria provided by the pedagogic model, attributing them commonsensical meanings and using localised, non-specialised commentary to justify evaluations. We should stress that we do not place a value on 'consistency' or 'inconsistency' in teachers' practices. The discourse we have attempted to describe makes contradictory demands on the positions it creates. Evaluating would be inappropriate, given our accord with Bernstein's insistence that research should be directed to systematic description.

Figure 2 here

We can now use this figure to render Morgan's categorisation scheme, as shown in Figure 3. 
The two-way matrix in Figure 2 is deliberately pared down, and so too will be the elaborated figure 3 which follows. The categorisation is based on our theoretical analysis, which combines structural and interactional features to describe the discourse of evaluation in terms of positions and forms of practice, respectively. The four cells derive from the projection of the model constructed in Figure 2 onto the empirical categories identified by Morgan. Each cell explains a category of teacher in terms of the position adopted in the discourse and the discursive resources used to deploy strategies: orientation (student/text), focus (present/absent) and criteria of assessment. The (reduced) model thus incorporates and explains theoretically four of the categories originally identified by Morgan: teacher adviser; teacher advocate; examiner using externally determined criteria; and examiner setting his/her own (professional) criteria.

When we say that the model helps us explain the categories we mean that it helps us to make systematic remarks on the empirical categories, and ultimately to read the text of interviews with teachers through the framework developed theoretically. Such observations and explanations of the data are:

The tendency, clearly identified in the data, for teachers to switch between student-present (teacher-adviser, teacher-advocate) and text-absence (the two positions of examiner).

The contradictions between the orientation-focus and the criteria employed (most clearly identified in the position of the teacher-adviser).

The contradictory demands created by the structural position adopted (voice) and the strategies employed. Such contradictions explain the actual compatibilities observed between the use of strategies 'properly' belonging to the legitimate discourse, and the voice of an alternative discourse in which a teacher speaks, and vice versa.

These incompatibilities characterise all four positions and are a function of the particular system of examination. The official discourse itself makes contradictory resources available and 
coursework assessment expresses this tension. Contradictory demands, then, are made when the teacher uses the resources of a competence model within examination structures that impose strategies that are more consistent with a performance model.

Furthermore, systematic remarks, facilitated by the use of this reduced model, might include the identification of the various strengths of the tendency to draw on non-specialised resources involved in (coursework) examination practices. This is the case, for example, of the 'teacher advocate'. This position, because it relies on resources that privilege localising strategies, might also make available resources from horizontal discourse (localised rather than specialised) as a basis for judgements. Other positions are clearly possible through further fragmentation.

Figure 3 here

The positions identified in Figure 3 are now elaborated, using examples from Morgan's data, illustrating how they may operate in practice.

\section{Examiner: using externally determined criteria}

Fiona:

This is a major problem because he's got these results but unless one is there in the class and you're a teacher you don't know whether this is his results or somebody else's. He hasn't shown any diagrams or where these results have come from.

Fiona is clearly speaking the voice of the official discourse. She refers to diagrams - an element of 'mathematical communication' valued in the official criteria - and to the notion of 
authenticating the work as belonging to the student - part of the officially stated work of teachers within the coursework assessment system. Orientation is towards the text and, consistently within a traditional pedagogic mode, the focus is on what is absent from the text. She refers explicitly to official criteria in interpreting the task of assessment. Contradictions inherent in the discourse are exemplified here. Coursework assessment is meant to be oriented to the student - the official discourse drawing on liberal-progressive resources to weaken official assessment practices and their consequences - but the criteria push this teacher's practice towards a text/absence orientation.

\section{Teacher-adviser}

Harry:

... he's also looked at the difference between each of the different piles. Now that straightaway will show him that there's a pattern there as well as the initial pattern. So that's something that would may come to when he's investigating later. Okay, so he's recognised that there is a pattern [...] there is a limitation because he's only gone up to ten units as the base; so that is something that he's considered that it may be just for this number of units. So making predictions over a hundred or so base units may be something he could mention as well.

The teacher-adviser speaks with the voice of the official discourse, in this case making use of notions of pattern and prediction, identified in the assessment criteria and other curriculum documents. The form of practice is, however, oriented towards the student and what is present in the text, reflecting the tension between performance and competence models within the official discourse. Rather than criticising the student for failing to draw more general conclusions, Harry points towards ways in which what the student has done might form the basis for further work. The official discourse is endorsed because the task of adviser is interpreted according to the 
generalised criteria offered by the discourse. However, use of the criteria is implicit and reference to pattern and prediction is not explicitly evaluative.

\section{Examiner: setting his/her own (professional) criteria}

\section{Carol:}

... it does say explain your working and it's true that the candidate has got the answer and hasn't just written down the answer and the explanation I find acceptable here. It's done just as a mathematical explanation. I think sometimes that word 'explain' causes problems. [...] So the fact that this student has used a simple calculation and left it at that actually at this stage makes me into an even more positive frame towards them because they see that a mathematical calculation can be sufficient explanation.

In this position, the teacher speaks with the voice of an unofficial discourse, adopting the values of a traditional pedagogic discourse (performance model), and endorsing calculation as explanation, rejecting the notion that 'explain' involves verbalisation. Orientation is towards what is absent in the student's text, identifying what is generally required but may be lacking. Carol explicitly rejects the official criteria and refers instead to her own professional values. But there is ambivalence about the sources that may be drawn upon in interpreting her role as examiner. Orientation towards performance models defeats the initial official purpose of coursework assessment, supposedly serving the interest of less privileged pupils.

\section{Teacher-advocate}

Andy:

The formula is accurate, needs a bracket in it, but it's quite clear that his intention and he's given a nice example which clarifies his thinking, so although algebraically it's not that strictly correct, it's quite clear he knows what he's doing. 
The teacher-advocate speaks with the voice of an unofficial discourse, valuing the supposition that the student knows what he's doing. Andy uses a discourse of competence, situating knowledge in the student's own activity. Consistent with this particular discourse voice, he is oriented towards the student through what is present in the text. It is likely that resources are drawn from populist or emancipatory modes, which value pupils' everyday meanings and practices (such as using examples) and in which teacher and pupils trust each other as members of a community.

Criteria encompassed in the mode of practice projected by the alternative discourse may tacitly operate, creating compatibilities and contradictions vis-à-vis the official criteria. The tendency to reject specialised and adopt localised criteria leaves room for commonsensical interpretations of aspects of the assessment task as pedagogic activity. In this case, Andy explicitly rejects official criteria such as correct notation, valorising thinking and understanding. Judgements about what the student knows are made confidently but relationships between these judgements and evidence in the text are not fully articulated. The operation of tacit criteria might well be grounded in commonsensical meanings.

The positions identified in Figure 3 are not exhaustive, but describe limit cases where the positions and resources available to these positions are identified and theoretically explained. Thus, in each example above, orientation towards the student is associated with strategies that involve focussing on what is present (consistent with competence models), while, conversely, orientation towards the text is associated with a focus on absences (consistent with performance models).

We have illustrated the four positions presented in Figure 3. We now provide an illustration of how some teachers in their positioning draw from everyday discourses. 


\section{Example of drawing upon horizontal (everyday) discourse:}

Joan:

I wonder, the fact that he's drawn that dotted line across the middle makes me think he was looking at it in terms of two trapeziums but he hasn't said that here [...] so that seems like a very sensible idea.

Here, Joan uses and values the notion that the student's apparent approach to the problem "seems like a sensible idea". This is not part of an explicitly educational discourse but draws on an everyday discourse in which "sensible" is a positive evaluative criterion. The aspects of the student's approach that make it sensible are not made explicit, although they could have been justified by drawing on resources from mathematics educational discourses such as analysing the problem, using deductive reasoning, etc.

Of the eight positions originally identified by Morgan (1998), the first four have been incorporated into the model proposed here and are now defined in theoretical terms. Of the others, we now see 'imaginary naive reader' as a strategy adopted in order to operationalise criteria rather than as a genuine position. 'Teacher/pedagogue' can be seen as a more general or less refined position that can be recategorised as either teacher/advocate or teacher/adviser or may arise from a less 'consistent' use of resources, for example, combining orientation towards the student with a focus on absences. The position of 'interviewee' is alienated from the assessment discourse in that a teacher is engaging in a practice that is not an assessment practice. Some examples of teachers apparently positioned as 'interested mathematicians' are similarly seen to be in alienated positions, while most are re-categorised as speaking with the voice of an unofficial discourse (either teacher/advocate or examiner, setting and using their own criteria, depending on their orientation). 


\section{CONCLUSIONS}

In this final section we will examine what has been gained by revisiting the data and analysis in Morgan (1998). The original classification of positions was derived empirically and was not systematic, failing to establish links between the positions adopted by teachers and other aspects of their practice. Setting the classification in a theoretical framework has validated the empirical distinctions and identified the locations of the positions in official or oppositional pedagogic discourse or in alternative discourses, including the interview discourse. Thus the identification of the positions and discourses in play is less arbitrary. We can also reconsider the nature of tensions between discourses. Whereas Morgan identified tensions between a discourse of 'investigation' and a discourse of 'assessment', we now see this tension as being between liberal progressive and traditional modes of pedagogic discourse. Thus the model helps us describe teachers' assessment practices systematically, explaining apparent consistencies and inconsistencies.

The model was derived by systematic use of a theory seeking to understand how educational practices relay power and control relations and serve to reproduce or change them. Our main objective has been to reveal varieties of modalities of regulation (Bernstein, 2000) by modelling agencies, agents, practices and specialised forms of communication. The model consists of opposing forms according to the strength of power relations (examiner/teacher) and control relations (adviser/advocate). These positions are not ideal types; they are generated to assist in the description of the empirical.

In a more general sense the approach that we have provided enables a conversation between the theoretical and empirical fields of the research focus, and allows us to understand teachers' relationships to the discourses at play in evaluation practices. Beyond assessment, the theoretical framework allows us to take account of social forces when studying teaching, 
teachers, and differences between teachers. For example, it provides an alternative way of looking at teachers' beliefs, usually seen as private, individual belief systems (see Lerman, 2001).

The significance of the endeavour inheres in the possibility of raising questions about dominant policies, such as coursework, and investigating them in a systematic way. Bernstein's framework enables a more elaborated language for describing the mechanisms whereby social forces impact upon schooling. Without such a language, connections with the ideologies of social groups remain covert, hindering possibilities of resistance. We contend that the framework developed here can enable teachers to examine the sources of their attitudes to assessment. By doing this, practices can be changed as teachers recognise how success and failure are constructed within different pedagogic modes. The question of whether teachers recognise the form of pedagogy they draw on, the sources of the pedagogy and the special demands or requirements is not only a substantive issue (Morais, Fontinhas, Neves, 1992; Ensor, 1999; Solomon \& Tsatsaroni, 2001) but is also methodologically relevant: if a teacher recognises the sources of his/her pedagogy, this can counter the effects of the mediation of teacher assessment activity in the interview situation.

The analysis can also be applied in other educational contexts. ${ }^{2}$ For example, in considering the National Numeracy Framework, being implemented in all primary classrooms in the UK by central government pressure, analysis of the OPRF and the UPRF enables us to study the

\footnotetext{
${ }^{2}$ The model is currently being developed to be applied to a study of the production and use of theories in mathematics education research (ESRC project no. R000223610). In addition a follow-up to project Teaching and Learning - Mathematical Thinking proposes to apply the model to new data collected in Portuguese and English mathematics classrooms.
} 
positions available to teachers, again enabling avenues of resistance. More generally, curriculum innovations in any subject offer researchers interesting possibilities since the visibility of different discourses is greater than when practices are strongly established.

To conclude, our concern in this article has been with using theory to further develop the methodological approach to an empirical study. This required us to engage with analysis of the construction of the discourse. Attempting to explain what interests such a discourse serves (or what changes in society give rise to such a discourse) goes beyond the aims of the present work. However, we are aware that Bernstein would invite us not simply to analyse the elements of the discourse as two competing ideologies (cf. Broadfoot, 1998), but also to ask what social fractions promote them, what class assumptions underpin them. This would elaborate more clearly the effects of the discourse and whether it serves to empower or disempower teachers and pupils (cf. Bernstein, 1990). 


\section{REFERENCES}

BERNSTEIN, B. (1971) On the classification and framing of educational knowledge, in: M.F.D YOUNG (Ed) Knowledge and Control (London, Collier-Macmillan).

BERNSTEIN, B. (1990) The Structuring of Pedagogic Discourse (London, Routledge).

BERNSTEIN, B. (1996) Pedagogy, Symbolic Control and Identity (London, Taylor \& Francis).

BERNSTEIN, B. (1999) Vertical and horizontal discourse: an essay, British Journal of Sociology of Education, 20(2), pp. 157-173.

BERNSTEIN, B. (2000) Pedagogy, Symbolic Control and Identity. (revised edition)(Lanham, Maryland, Rowman \& Littlefield).

BERNSTEIN, B. \& SOLOMON, J. (1999) 'Pedagogy, identity and the construction of a theory of symbolic control': Basil Bernstein questioned by Joseph Solomon, British Journal of Sociology of Education, Vol. 20(2), pp. 265-279.

BROADFOOT, P. (1996) Education, Assessment and Society: A sociological analysis (Buckingham, Open University Press).

BROADFOOT, P. (1998) Quality standards and control in Higher Education: what price lifelong learning? International Studies in Sociology of Education, Vol. 8(2), pp.155-180.

BROADFOOT, P. (2000) Culture, learning and comparison: Lawrence Stenhouse's vision of education for empowerment, BERA Stenhouse Lecture (Southwell, British Educational Research Association).

BROWN, A. J. (1999) Parental participation, positioning and pedagogy: a sociological study of the IMPACT primary school mathematics project, Collected Original Resources in Education, 24 (3) (7/A02-11/C09). 
DOWLING, P. (1998) The Sociology of Mathematics Education (London, Falmer).

EDEXCEL. (1999) Mathematics 1385 and 1386: The Assessment of Ma1 (London, Edexcel Foundation).

ENSOR, P. (1999) A study of the recontextualising of pedagogic practices from a South African University preservice mathematics teacher education course by seven beginning secondary mathematics teachers, Unpublished PhD Thesis, University of London.

LAMNIAS, C \& TSATSARONI, A. (1999) School knowledge and practices of assessment: their role with respect to pupils' failure and social exclusion, in: C. KONSTANTINOU \& G. PLEIOS (Eds) Proceedings of $8^{\text {th }}$ International conference of the Greek Pedagogical Association, 'School Failure and Social Exclusion' (Athens, Ellinika Grammata (in Greek)).

LERMAN, S. (2001) A review of research perspectives on mathematics teacher education, in: FL LIN \& T. COONEY (Eds) Making Sense of Mathematics Teacher Education (Dordrecht, Kluwer).

LERMAN, S. \& TSATSARONI, A. (1998) Why children fail and what mathematics education studies can do about it. The contribution/role of sociology, in: P. GATES (Ed) Mathematics Education and Society, Proceedings of the First International Mathematics Education and Society Conference (MEAS1) (Nottingham, Centre for the Study of Mathematics Education, Nottingham University).

MATON, K. (2000) Languages of legitimation: The structuring significance for intellectual fields of strategic knowledge claims, British Journal of Sociology of Education, Vol. 21(2), pp. 147-167.

MACNAMARA, A. \& ROPER, T. (1992) Unrecorded, unobserved and suppressed attainment: Can our pupils do more than we know? Mathematics in School, 21(5), pp. 12-13. 
MOORE, R. \& MATON, K. (2001) Realising potential: Basil Bernstein, intellectual fields and the epistemic device, in: A. MORAIS, I. NEVES, B. DAVIES, \& H. DANIELS, (Eds), Towards a sociology of pedagogy: The contribution of Basil Bernstein to research (New York, Peter Lang).

MOORE, R. \& MULLER, J. (1999) The Discourse of 'voice' and the problem of knowledge and identity in the sociology of education, British Journal of Sociology of Education, 20(2), pp. 189-206.

MORAIS, A. M., FONTINHAS, F. \& NEVES, I. P. (1992) Recognition and realization rules in acquiring school science: The contribution of pedagogy and social background of students, British Journal of Sociology of Education, 13 (2), pp. 247-270.

MORGAN, C. (1996) Teacher as examiner: The case of mathematics coursework, Assessment in Education, 3(3), pp. 353-375.

MORGAN, C. (1998) Writing Mathematically: The Discourse of Investigation (London, Falmer).

MORGAN, C. (2000a) Discourses of Assessment - Discourses of Mathematics, in: J. F. MATOS \& M. SANTOS (Eds), Proceedings of the Second International Mathematics Education and Society Conference (Lisbon, Centro de Investigação en Educação, Faculdade de Ciências da Universidade de Lisboa).

MORGAN, C. (2000b) Better assessment in mathematics education? A social perspective, in: J. BOALER (Ed), Multiple Perspectives on Mathematics Teaching and Learning (Westport, CT, Ablex).

ROMBERG, T. A. (Ed). (1995) Reform in School Mathematics and Authentic Assessment (New York, SUNY Press). 
SOLOMON, J. \& TSATSARONI, A. (2001) Educational evaluation: The social production of texts and practices, in: A. MORAIS, I. NEVES, B. DAVIES, \& H. DANIELS, (Eds), Towards a sociology of pedagogy: The contribution of Basil Bernstein to research (New York, Peter Lang).

WATSON, A. (1999) Paradigmatic conflicts in informal mathematics assessment as sources of social inequity, Educational Review, 51(2), pp. 105-115. 


\section{CAPTIONS TO FIGURES}

Figure 1: Fields and sub-fields in the production of the discourse of evaluation

Figure 2: Positions and practices in discourses of assessment

Figure 3: Teachers' subject positions in the Education Discourse and their orientation in assessment practice 


\section{FIGURE 1}

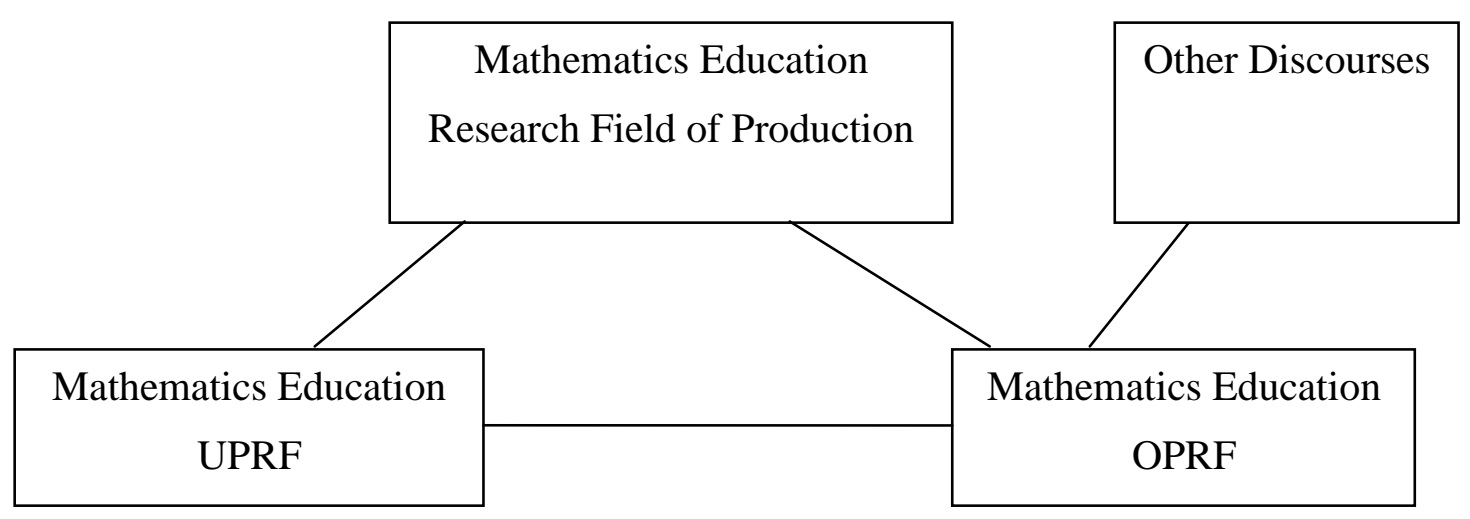

Recontextualising Fields of Mathematics Classrooms 


\section{FIGURE 2}

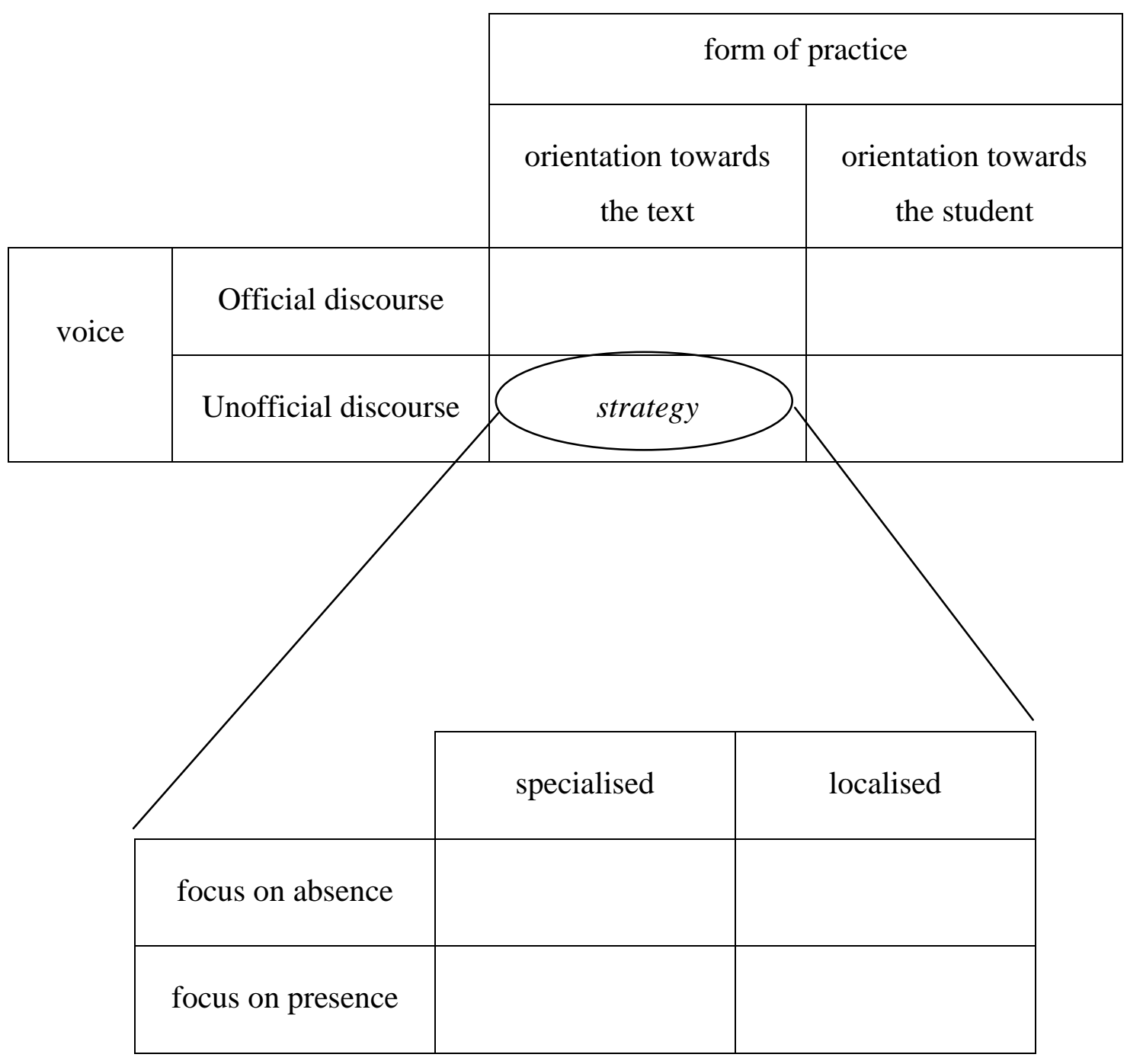




\section{FIGURE 3}

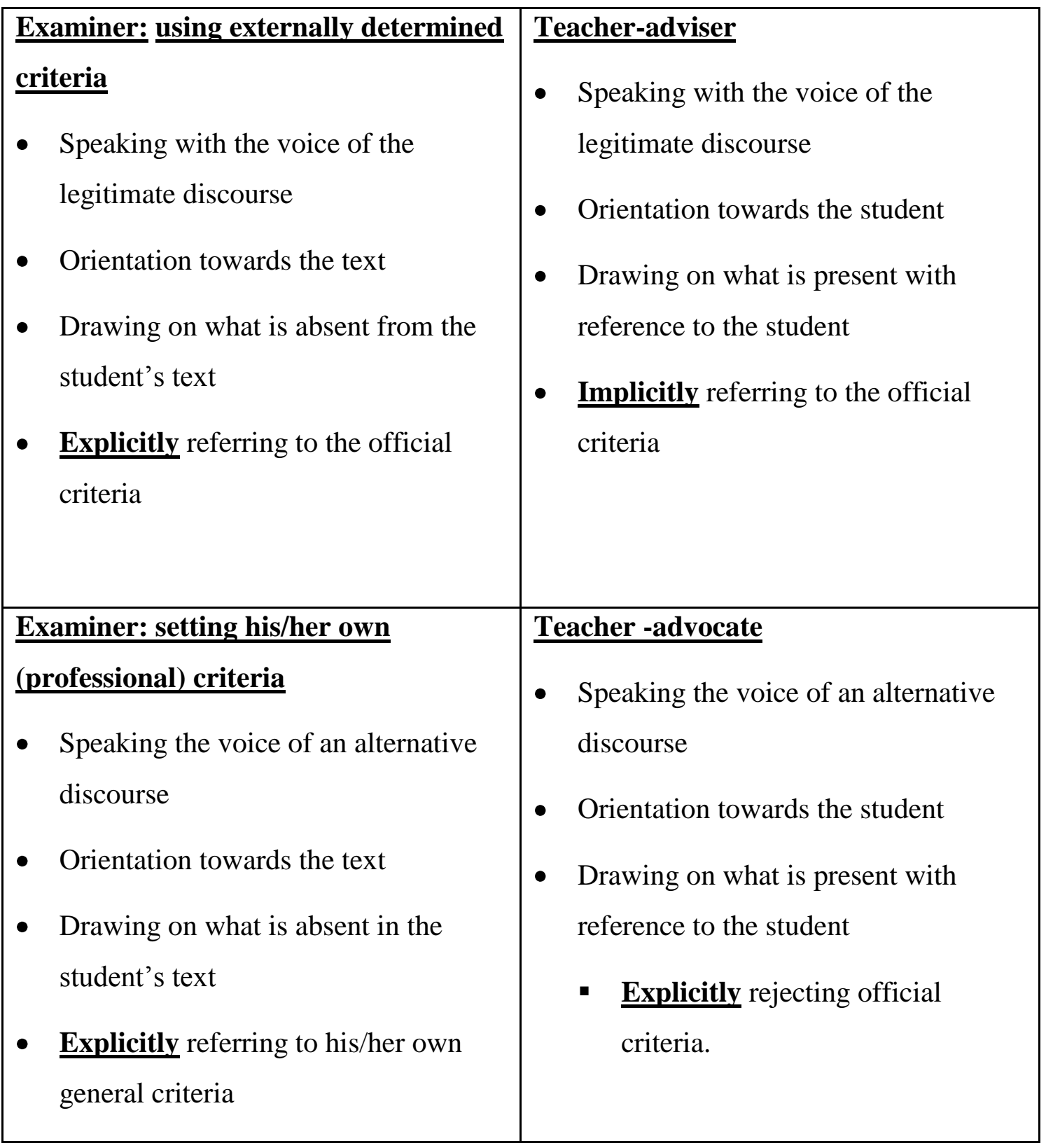

